See Article page 1497.

\section{Commentary: Think systemically, act locally}

\section{Brendon M. Stiles, MD}

It is open season on oligometastatic cancer. Spurred on by a handful of key publications, the concept of local consolidative therapy (LCT) for patients with metastatic lung cancer is gaining traction. A search of ClinicalTrials.gov for the 2 terms yields 37 trials, the vast majority utilizing stereotactic radiation therapy rather than surgery for LCT. The definition of oligometastatic itself seems to be a moving target, with initial studies defining oligometastatic as either 1 to 3 lesions or 1 to 5 lesions, whereas newer studies push the number even higher. ${ }^{1,2}$ In this context, it is important to understand the data and existing limitations on LCT. The trial reported by Gomez and colleagues ${ }^{1}$ was a multicenter, phase II study of 74 patients with stage IV lung cancer who did not progress after initial systemic therapy, subsequently randomized to LCT (ie, radiation therapy or resection of all lesions) or standard therapy. LCT patients had longer progression free survival (11.9 months vs 3.9 months; hazard ratio, $0.35 ; 95 \%$ confidence interval, 0.18-0.66). Despite that impressive difference, the number of patients was small, the inclusion criteria were broad, and most importantly progression free survival may not be the best surrogate for efficacy given that sites of potential progression were all treated in 1 of the arms and not the other, making radiographic assessment distinct between the 2 arms. In Stereotactic Ablative Radiotherapy versus Standard of Care Palliative Treatment in Patients with Oligometastatic Cancers, another randomized phase II trial (this time only using stereotactic radiation for LCT), the authors did show a strong trend toward a difference in overall survival favoring LCT (41 months vs 28 months; hazard ratio, 0.57 ; 95\% confidence interval, 0.30-1.10). ${ }^{2}$ However, the trial included patients with multiple tumor types and differing numbers of metastases that were unbalanced between

\footnotetext{
From the Department of Cardiothoracic Surgery, Weill Cornell Medicine, New York-Presbyterian Hospital, New York, NY.

Disclosure: Dr Stiles has received consulting/speaker fees from AstraZeneca, Pfizer, Bristol Myers Squibb, Ribon Therapeutics, Gala Therapeutics, WebMD, and Medtronic and his spouse receives salary/stock from Pfizer and PPD.

Received for publication Feb 23, 2020; accepted for publication Feb 24, 2020; available ahead of print March 12, 2020.

Address for reprints: Brendon M. Stiles, MD, 525 E 68th St, Greenberg Pavilion, M404, New York, NY 10065 (E-mail: Brs9035@med.cornell.edu).

J Thorac Cardiovasc Surg 2021;161:1505-6 0022-5223/ $\$ 36.00$

Copyright (c) 2020 Published by Elsevier Inc. on behalf of The American Association for Thoracic Surgery

https://doi.org/10.1016/j.jtcvs.2020.02.109
}

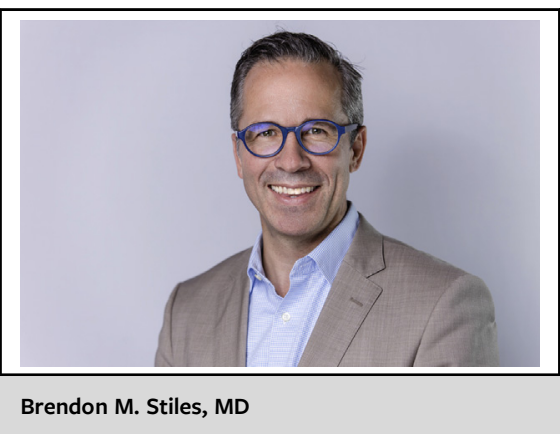

CENTRAL MESSAGE

Surgery remains a good option

for local consolidative therapy

for select patients with metasta-

tic lung cancer.

arms. Additionally, there were more adverse events in the LCT arm and a reported $4.5 \%$ rate of treatment-related death in the stereotactic radiation group.

Regardless of criticisms, there is an overwhelming interest in stereotactic radiation therapy for LCT for oligometastatic lung cancer. This is based on the low early treatment-related morbidity and presumed excellent local control ( $>90 \%)$ of stereotactic radiation. However, Mitchell and colleagues ${ }^{3}$ remind readers not to forget surgery as an option for local control, pointing out that in experienced hands surgery is associated with low perioperative mortality and excellent long-term results in this setting. In their retrospective study of select patients with metastatic lung cancer undergoing surgery $(n=25)$, there were 0 mortalities at 90 days and the median postoperative survival time was 55.2 months, with a 5-year overall survival of $48 \%$. Clearly, patient selection matters and a criticism should be that perhaps patients were too carefully selected, with only 25 patients undergoing operation in 18 years. Selection bias therefore makes it impossible for us to draw any conclusions regarding overall efficacy of LCT. Nevertheless, by comparing these patients with those treated with radiation therapy at their center who were also carefully selected (albeit differently) over the same time period, the authors make the important point that results with surgery at least seem potentially comparable to those achieved with radiation therapy. How then should we decide whether the local in LCT should be surgery or radiation? 
Undoubtedly, this is a difficult, patient-specific question that will ultimately require randomized data to answer. In the lung, for tumors or lymph node metastases that require conventionally fractionated radiation therapy rather than stereotactic radiation, given the expected higher local failure rate and morbidity of conventional radiation, one might instead consider surgery if the disease burden is resectable by lobectomy. Alternatively, if it is believed that a pneumonectomy is needed to obtain an $\mathrm{R} 0$ resection, radiation therapy would seem to be a rational choice given the potentially high morbidity and mortality following pneumonectomy at many centers. I hypothesize that the molecular status and systemic treatment utilized for individual patients might also be important. Radiation therapy, because of the delayed cell kill and potential immune priming effect, may ultimately become the LCT treatment of choice for patients treated with immunotherapy. However, for patients with specific driver mutations treated with targeted therapy (eg, epidermal growth factor receptor mutations and anaplastic large-cell lymphoma kinase rearrangements) in whom known resistance mutations evolve in small subpopulations of cells, complete early eradication of all of the disease becomes more critical. The $60 \%$ complete pathological response rate reported after stereotactic radiation in the Measuring the Integration of Stereotactic Radiotherapy Plus Surgery in Early-Stage Non-Small Cell Lung Cancer trial (acknowledging the possibility that there could potentially be ongoing cell kill after 10 weeks), may not be adequate to avoid acquired resistance in persister cells in these patients' tumors. ${ }^{4}$ Perhaps in those situations surgery should be favored if it can be done safely. Either way, as systemic control continues to improve and as patients with metastatic lung cancer live longer on targeted therapy or immune checkpoint blockade, I agree with the authors that locoregional control will become more important. LCT is here to stay.

\section{References}

1. Gomez DR, Blumenschein GR, Lee JJ, Hernandez M, Ye R, Camidge DR, et al. Local consolidative therapy versus maintenance therapy or observation for patients with oligometastatic non-small cell lung cancer without progression after first-line systemic therapy: a multicenter, randomized, controlled phase 2 study. Lancet Oncol. 2016;17:1672-82.

2. Palma D, Olson R, Harrow S, Gaede S, Louie AV, Haasbeek C, et al. Stereotactic ablative radiotherapy versus standard of care palliative treatment in patients with oligometastatic cancers (SABR-COMET): a randomized, phase 2, open-label trial. Lancet. 2019;393:2051-8.

3. Mitchell KG, Farooqi A, Ludmir EB, Corsini EM, Sepes B, Gomez DR, et al. Pulmonary resection is associated with long-term survival and should remain a therapeutic option in oligometastatic lung cancer. J Thorac Cardiovasc Surg. 2021; 161:1497-504.e2.

4. Palma DA, Nguyen TK, Louie AV, Malthaner R, Fortin D, Rodrigues GB, et al. Measuring the integration of stereotactic ablative radiotherapy plus surgery for early-stage non-small cell lung cancer: a phase 2 clinical trial. JAMA Oncol. 2019;5:681-8. 